\title{
La guerra contra el Estado Islámico y la opinión pública en Estados Unidos
}

\author{
Editado por/Edited by: Gabriela Albuja/Alejandro Borja \\ Recibido/Received: 9/11/2014. Aceptado/Accepted: 16/05/2015 \\ Publicado en línea/Published on Web: 16/10/2015
}

\author{
María Gracia Naranjo \\ Universidad San Francisco de Quito, Colegio de Jurisprudencia JUR \\ Diego de Robles y Vía Interoceánica, Quito, Ecuador \\ Correo Electrónico: mariagracianaranjo@gmail.com
}

\section{Resumen}

El 23 de septiembre de 2014, Barack Obama declaró el inicio de una nueva guerra contra el terrorismo en Irak y Siria para combatir al Estado Islámico. Hasta el momento, un alto porcentaje de estadounidenses apoya el inicio de esta nueva guerra. Este ha sido un patrón constante en las guerras en las cuales Estados Unidos se ha visto involucrado en las últimas décadas: Corea, Vietnam, Irak y Afganistán. La opinión pública, en un inicio, ha favorecido la decisión de iniciar ataques militares. Sin embargo, ésta no ha sido una tendencia que se ha mantenido mientras estas guerras han seguido avanzando y sus costos han ido aumentando. La guerra de Irak es un claro ejemplo de lo mencionado; en el 2003, cuando la guerra inició, el 70\% de la ciudadanía apoyaba la decisión del gobierno, mientras que en el 2013, 13 años más tarde, solamente un 35\% de la población seguía considerando que la guerra era necesaria. A pesar de que la opinión pública no parece ser relevante para quienes diseñan las estrategias de seguridad nacional en Estados Unidos, resulta interesante analizar que entre la ciudadanía sí existe debate, discrepancia y cuestionamientos sobre la intervención militar en Siria e Irak ¿Cuáles son los factores que generan cambios en el apoyo hacia las acciones militares? ¿En la guerra contra el Estado Islámico, influenciarán estos factores de la misma manera que lo hicieron en guerras pasadas de similar naturaleza?

Palabras clave: Estado Islámico, opinión pública, terrorismo, Irak, Afganistán, percepciones cambiantes

\footnotetext{
Abstract

On the 23rd of September of 2014, Barack Obama declared the beginning of a new war against terrorism in Iraq and Syria, with the objective of fighting the Islamic State (ISIS). A high percentage of Americans support this new war. This has been a consistent pattern in the wars in which the United States has been involved in the past decades: Korea, Vietnam, Iraq and Afghanistan. Public opinion, at first, supported the decision of launching military attacks. However, this trend has not been maintained as these wars have advanced and their costs continued to increase. The war in Iraq is a clear example of this pattern; in 2003, when the war began, $70 \%$ of the public supported the government's decision of launching a military campaign, while in 2013 , 13 years later, only $35 \%$ of the population still believed that the war was necessary. Although the public opinion does not seem to be relevant to those who design the national security strategies in the United States, it is interesting to note that among the citizenry, there is debate, dissent and questioning about the current military intervention in Syria and Iraq. What are the factors that drive these changes in public support for military actions? In the war against the Islamic State, will these factors influence in the way they did in other recent wars of similar nature?
}

Keywords: Islamic State, public opinion, terrorism, Iraq, Afghanistan, changing perceptions. 


\section{La guerra contra terrorismo y la opinión públi-} ca

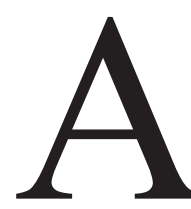
partir de los atentados terroristas del $11 \mathrm{de}$ septiembre de 2001, Estados Unidos ha enfocado sus estrategias de seguridad nacional en el combate contra el terrorismo con miras a eliminar a aquellos grupos que se presentan como amenazas (Kumar, 2012, p. 113). Como explica Yolanda Gamarra:

Un año después de los atentados terroristas del 11 de septiembre de 2001 de Nueva York, Washington D.C y Pennsylvania, la Administración de Bush hizo pública su estrategia de seguridad nacional en la cual, por medio de la exaltación de los valores de libertad, democracia, justicia e igualdad, se afirmaba el derecho de Estados Unidos a utilizar su poder militar como medida preventiva contra todo Estado considerado una amenaza para la seguridad global a causa del terrorismo (Gamarra, 2007, p. 227).

Con este objetivo, Estados Unidos emprendió una serie de acciones militares. La guerra de Afganistán, que comenzó pocos meses después de los ataques del 11 de septiembre, fue la primera; seguida por la guerra en Irak, la cual inició en 2003. A partir de 2014, una nueva guerra o "estrategia ofensiva" se encuentra dentro de las prioridades de seguridad nacional de Estados Unidos: la guerra contra el Estado Islámico (EI) en el norte de Irak y en Siria.

A inicios de septiembre de 2014, el presidente estadounidense Barack Obama anunció la intervención de Estados Unidos en la guerra contra el Estado Islámico, liderando una coalición internacional con el mismo fin. Muchos aspectos de la guerra contra el terrorismo por parte de Estados Unidos han generado debate y opinión, tanto en la política nacional estadounidense como en el ámbito de la política y relaciones internacionales.

Uno de los asuntos relevantes de la guerra contra el terrorismo se relaciona con la opinión pública en Estados Unidos, pues las tendencias de apoyo popular hacia las acciones militares estadounidenses han sido sumamente variables pero seguido un patrón similar, casi idéntico, en las diferentes guerras. El presente ensayo busca analizar los patrones de opinión pública de las guerras más recientes en las que el país se ha visto involucrado e identificar las principales causas de variación de la misma, y de esta manera, examinar las tendencias de opinión pública sobre la recientemente emprendida guerra contra el Estado Islámico y determinar los posibles patrones futuros de la opinión pública sobre esta guerra. El artículo sostiene, principalmente, que esta guerra mantendrá patrones de opinión pública similares a los reflejados en guerras pasadas como Afganistán e Irak, es decir, un apoyo a elevado al inicio y un decrecimiento constante.

\section{Opinión pública y política exterior en Estados Unidos}

La opinión pública es un término notoriamente complejo y difícil de definir, como consecuencia de la inmensa cantidad de variables que intervienen en la formación de la misma. Sin embargo, hay una serie de elementos comunes en las definiciones existentes sobre la opinión pública. Primero, la opinión púbica involucra la expresión de una actitud o postura frente a un asunto en específico por parte de los ciudadanos de un país. Estas posturas están generalmente influenciadas por valores, creencias u opiniones personales o colectivas. Segundo, el asunto sobre el cuál los individuos mantienen una postura debe ser de interés político o estar relacionado con temas gubernamentales (Erikson \& Tedin, 2011, p. 6). Finalmente, la opinión pública es una fuerza sumamente variable, porque las opiniones que los individuos mantienen no son constantes, incluso el grupo de ciudadanos que se considera como 'público' varía frecuentemente entre una situación y otra (Bennett \& Barber, J. D, 1980, p 12).

El estudio de la opinión pública es vital en las sociedades democráticas, pues constituye un elemento importante en la legitimidad de las políticas diseñadas por quienes ocupan cargos de poder. Éste busca analizar cómo los individuos forman juicios individuales o colectivos sobre problemas u objetivos del Estado, y explorar los procesos complejos mediante los cuáles la opinión pública varía en torno a determinados asuntos (Bennett \& Barber, J. D, 1980, p. 8).

En Estados Unidos, específicamente, la opinión pública es sumamente relevante pues cómo resaltan Shapiro y Jacobs, ésta tiene sus raíces en los orígenes de la visión estadounidense de la democracia (2011, p. 269). La importancia de la opinión pública en los procesos políticos es proclamada explíci- 
tamente en la Constitución estadounidense y afirmada implícitamente en las continuas expectativas que los ciudadanos depositan en su gobierno (Bennett \& Barber, 1980, p 1).

Su verdadera influencia en la toma de decisiones es debatible, sobre todo con relación a asuntos de política exterior. Muchos académicos consideran que la opinión pública influye directamente en la toma de decisiones, e incluso afirman que es el elemento constitutivo de las políticas publicas (Stimson et al., 1995, 557, en Burstein, 2014, p. 5). Otros autores, por el contrario, afirman que es un elemento que no es tomado en cuenta en los procesos de toma de decisiones (Burstein, 2014, p. 5), o en muchos casos, que es utilizado únicamente con fines políticos, tales como la reelección.

Similarmente, estudios revelan que la opinión pública en Estados Unidos no siempre tiene una implicación significativa en la política, debido a que los actores políticos desconfían de la capacidad de los ciudadanos de emitir opiniones razonadas sobre asuntos políticos. En un estudio realizado en 1998 por Pew Research Center, por ejemplo, se determinó que solamente el $32 \%$ de los miembros del congreso, el $13 \%$ de los designados presidenciales y el $14 \%$ de los funcionarios públicos confían en la capacidad de los ciudadanos estadounidenses para tomar decisiones sobre cuestiones relacionadas con las políticas públicas y la política exterior (Dimaggio, 2010, p. 205).

Su verdadera influencia, por tanto, es difícil de ser identificada, y no constituye el objeto del presente análisis. Sin embargo, el análisis de los patrones y variaciones de la misma sobre temas cruciales sigue siendo relevante. Es un hecho que los individuos de la sociedad estadounidense construyen opiniones coherentes y razonadas en base a sus preferencias, que pueden estar acordes o no con las políticas que el país mantiene (Gelpi, Reifler \& Feaver, 2009, p. 241).

En el caso de las guerras contra el terrorismo en Estados Unidos, por ejemplo, la opinión pública resulta de interés tanto por la creciente preocupación ciudadana por las amenazas terroristas como por la complejidad política de las estrategias militares. El fenómeno de la opinión pública en torno a estas guerras es interesante, porque a diferencia de otros temas de política nacional e internacional en los cuales la opinión se modifica sin ningún patrón a lo largo del tiempo conforme las preferencias y los valores sociales cambian, se ha evidenciado que ésta se ha caracterizado por elementos similares y ha sufrido las mismas variaciones en las diferentes guerras, lo cuál nos permite realizar predicciones sobre guerras futuras.

A pesar de la existencia de innumerables posturas frente a las mismas, los estudios y las encuestas de opinión apuntan a identificar la existencia de dos principales grupos de actores de la opinión pública: aquellos que favorecen las estrategias militares emprendidas contra grupos terroristas y aquellos que se oponen a las mismas. Estos grupos, por supuesto, no tienen una composición constante y están compuestos por individuos que cambian sus posturas con frecuencia. Esa es, precisamente, la razón por la cuál resulta de interés estudiar la opinión pública con relación a estas guerras; la composición de los grupos que favorecen y que se oponen a las estrategias militares contra el terrorismo ha variado con patrones similares en las distintas guerras que Estados Unidos ha emprendido contra el terrorismo.

\subsection{Opinión pública sobre la guerra contra el Estado Islámico}

La percepción del Estado Islámico como una fuerza militar violenta y brutal es generalizada entre la población estadounidense, así como las motivaciones de Estados Unidos para intervenir en la guerra contra el Estado Islámico son sumamente variadas. Primeramente, el grupo militar desestabiliza a una región donde Estados Unidos tiene importantes aliados, como Israel y Jordania. Por otro lado, éste se muestra como una potencial amenaza para la seguridad nacional estadounidense y la seguridad global en general, en el marco de posibles ataques terroristas.

El terrorismo internacional en sí representa un tipo único de crisis desde la perspectiva de la política exterior. A diferencia de las amenazas internacionales clásicas, las amenazas de grupos terroristas son dispersas, tanto en términos organizacionales como geográficos lo cual implica mayores dificultades al momento de diseñar estrategias para. Los Estados que enfrentan estas amenazas, por tanto, diseñan sus estrategias con miras a erradicar los mencionados grupos, y justifican sus políticas en base a la teoría de actuar militarmente en el plano internacional para proteger en el plano local (Merolla \& Zechmeister, 
2009; p. 159).

De acuerdo a la encuesta realizada por Rasmussen Reports a finales de agosto de 2014, el $67 \%$ de los estadounidenses considera que el Estado Islámico es una amenaza seria para la seguridad nacional de Estados Unidos. Solamente un 13\% se encuentra en desacuerdo, mientras que un $20 \%$ no está seguro (Rasmussen Reports, 2014). Durante la misma semana, tras la conferencia de prensa en la cual Barack Obama estableció que Estados Unidos no cuenta con una estrategia específica para combatir al grupo terrorista, se realizó una encuesta en la que se buscaba evidenciar la preocupación de los ciudadanos ante esta afirmación. Los resultados mostraron que un $73 \%$ de estadounidenses considera preocupante que Estados Unidos no tenga una estrategia para combatir al grupo militar, mientras que solo un $25 \%$ respondió que no tienen preocupaciones al respecto (Rasmussen Reports, 2014).

A principios de septiembre de 2014, el presidente Barack Obama autorizó el inicio de ataques aéreos para combatir al Estado Islámico, y consideró la posibilidad de enviar tropas a Irak. En principio, esta alternativa no contaba con un apoyo mayoritario entre los estadounidenses, sin embargo, se convirtió poco a poco en una alternativa más atractiva. Hasta diciembre de 2013 , el $71 \%$ de estadounidenses se oponía al envío de tropas a Irak. A principios de agosto de 2014, la cifra decreció a 58\%, y a inicios de septiembre del mismo año, se encontraba alrededor de $41 \%$ (Rasmussen Reports, 2014).

Un punto crucial y coyuntural en la opinión pública sobre esta guerra fue, sin duda alguna, la decapitación de los periodistas estadounidenses James Foley y Steven Sotloff. Esto contribuyó con el aumento de las cifras de la opinión pública en cuanto a la consideración del Estado Islámico como una amenaza para la seguridad nacional de Estados Unidos, pues se presentó como una muestra de que la violencia que el Estado Islámico genera en el medio oriente puede llegar fácilmente al continente americano. De acuerdo a la encuesta realizada por $N B C$ News/ Wall Street Journal, a inicios de septiembre de 2014, el $94 \%$ de estadounidenses respondió haber escuchado la historia de estos periodistas y estar de alguna manera al tanto del asunto (Hart Research Associates, 2014). En este sentido, la noticia fue catalogada por el
Washington Post como una de las historias más visibles dentro de los últimos 5 años.

Como se evidenciará a continuación, donde se realizará una comparación de estas cifras con aquellas presentadas al inicio de guerras similares, la guerra contra el Estado Islámico inicia con un apoyo popular similar al que tuvieron las dos guerras contra el terrorismo más recientes: Irak y Afganistán. Una vasta mayoría de la ciudadanía muestra su preocupación por las amenazas que, desde su perspectiva, presenta el terrorismo, y por tanto, favorecen una intervención militar que les ofrece "degradar y finalmente destruir" la mencionada amenaza. Si bien los conflictos difieren entre sí en términos de su naturaleza, tanto la guerra en Afganistán como la guerra en Irak son casos interesantes para analizar en términos de opinión pública pues ambas iniciaron como una respuesta a los ataques terroristas del 11 de septiembre de 2001, como lo hace la actual intervención militar contra el Estado Islámico.

\subsection{Opinión pública sobre guerras pasa- das: Irak y Afganistán}

La guerra en Afganistán tuvo como objetivo combatir al gobierno talibán y a los líderes de Al Qaeda. La acción militar consistió principalmente en ataques militares tanto aéreos como terrestres. Tras la derrota del gobierno talibán, la presencia de Estados Unidos en Afganistán permaneció activa, pues las reagrupaciones talibanes aumentaron su actividad como consecuencia de la no aceptación del nuevo gobierno auspiciado por Estados Unidos.

La guerra en Irak, en cambio, empezó un año y medio después de lo sucedido el 11 de septiembre, en marzo de 2003. Las motivaciones de iniciar esta guerra se basaban en las sospechas, no confirmadas, de la participación de Saddam Hussein, ex Primer Ministro de Irak, en el mencionado ataque terrorista. Estados Unidos buscaba, por tanto, un cambio de régimen en Irak, y consecuentemente, derrotar a Hussein. La intervención militar se basó en la premisa de que Irak mantenía un programa de armas de destrucción masiva, incluyendo armas nucleares, que podría ser utilizado para futuros ataques terroristas en contra de

1 Términos utilizados por el presidente Barack Obama en su comunicado oficial sobre el Estado Islámico en septiembre de 2014 (http://www.whitehouse.gov/the-press-office/2014/09/10/ statement-president-isil-1) 
Estados Unidos o sus aliados (Kumar, 2012, p. 113).

La intervención militar en Irak fue mayor que la intervención en Afganistán. Estados Unidos, junto a sus aliados, logró derrotar a Hussein y tomar control de las ciudades más importantes de Irak. Pronto se desacreditó la teoría de que Hussein mantenía un programa de armas de destrucción masiva, por lo que la administración de Bush cambió el enfoque de legitimación de su intervención mencionando que la guerra en Irak era el frente de una guerra contra el terrorismo global, y un intento de esparcir la democracia en el Medio Oriente, con el fin de alcanzar la paz en la región. El mencionado objetivo fue poco exitoso, y eso llevó al aumento de tropas en la región. De esta manera, a diferencia de la guerra en Afganistán, cuyas motivaciones eran tanto castigar como incapacitar a Bin Laden, el fundador de Al Qaeda, y a otros líderes de la organización, la guerra en Irak buscaba eliminar futuras amenazas terroristas (Kumar, 2012, p. 113).

Las cifras evidencian que, en las guerras en las que Estados Unidos se ha involucrado en el pasado, el apoyo popular ha sido sumamente elevado. Sin embargo, el mencionado apoyo favorable fue decreciendo a medida que las guerras se fueron desarrollando. Estas intervenciones fueron inicialmente populares entre la población estadounidense, pero terminaron en un fracaso político y en decepción popular. La desintegración del apoyo hacia estas guerras sigue patrones notablemente similares en ambos casos (Tirman, 2011, p. 5).

\subsubsection{Tendencias de opinión pública}

Sin caer en inobservancia del hecho de que estas guerras han tenido motivaciones variadas, la opinión favorable ha sido una característica constante en el inicio de las guerras pasadas. Cuando la guerra de Irak inició en 2003, el apoyo de los estadounidenses se encontraba alrededor del $72 \%$ de la población. En junio de 2005, sin embargo, menos del 50\% de la población apoyaba el conflicto (Eichenberg, 2005; p. 140). La guerra en Irak y la ocupación militar plantearon dudas sobre la sostenibilidad del apoyo público a la intervención militar, pues al final de esta guerra casi el $60 \%$ de la población consideró que Estados Unidos no debió haber enviado fuerzas militares. Estas cifras, con relación a la guerra en Afganistán, se encuentran también alrededor del 50\% también (Gallup, 2014).
Al analizar las variaciones en la opinión pública conforme la guerra en Irak fue avanzando, resulta interesante no solo analizar su tendencia constante a decrecer sino también los hechos específicos que causaron las mencionadas variaciones momentáneas. En la Figura 1 se evidencia que ciertos eventos marcaron cambios drásticos en la opinión pública. El apoyo se redujo significativamente con eventos como la llegada del huracán Katrina, por ejemplo. El apoyo por la guerra aumentó, en cambio, tras concluir las exitosas elecciones en Irak, o tras los bombardeos en Londres.

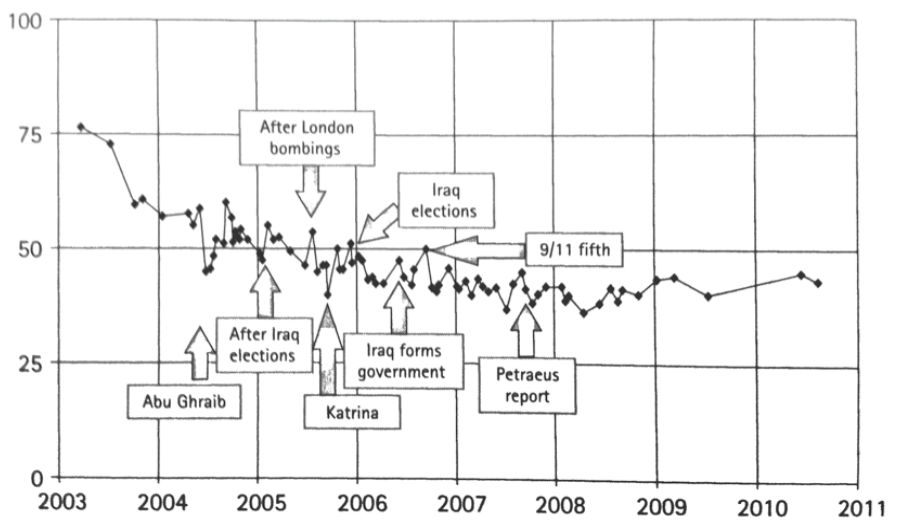

Figura 1. Tendencias de apoyo a la guerra en Irak entre 2003 y 2011, ante la pregunta: "Observando cómo se han desarrollado los hechos desde que se enviaron las tropas a Irak, ¿considera usted que los Estados Unidos cometió un error al enviar las tropas?" (Shapiro \& Jacobs, 2011, p. 680 ).

La Figura 1 evidencia ciertos patrones de variación en el apoyo popular. El apoyo disminuye cuando existen factores externos y no relacionados a la guerra que se presentan como urgentes y de mayor relevancia. Por el contrario, el apoyo aumenta cuando se obtiene algún resultado 'exitoso' de la misma; y aumenta también cuando la organización terrorista realiza un ataque, y por tanto, se reaviva la justificación inicial de la guerra (Shapiro \& Jacobs, 2011; p. 680).

El cambio en la opinión pública como consecuencia de la llegada del Huracán Katrina es un claro ejemplo de cómo la opinión pública puede variar y verse afectada por eventos que no tienen relación alguna con el conflicto. Ciertos eventos tienen influencia directa en la opinión pública sobre asuntos específicos, a pesar de no relacionarse con los mismos, por el simple hecho de presentarse como nuevos intereses domésticos que resultan prioritarios. 
El aumento del apoyo hacia la guerra en Irak como consecuencia de eventos como las elecciones exitosas en el país, o nuevos ataques en países aliados, evidencia la importancia que tiene el factor 'éxito' en las intervenciones militares. El apoyo a la actividad militar incrementa sustancialmente cuando se evidencian los frutos positivos de la misma, como ocurrió tras las elecciones en Irak. Como explica Eichenberg, si los Estados Unidos logra lo que se propone con estas guerras, los ciudadanos generalmente responden que la intervención fue necesaria. Si la misión falla, el público generalmente retira su apoyo (2005, p. 175). Ocurre algo similar cuando se presentan nuevos ataques, como evidencia la Figura 1 con relación a los atentados en Londres, los cuales sirvieron para resaltar la justificación inicial de la guerra, pues estos nuevos sucesos resaltan su importancia o necesidad.

\section{Factores determinantes en la variación de las tendencias de opinión pública}

La tendencia generalizada a la baja, siendo el enfoque principal del análisis de la opinión pública hacia las guerras contra el terrorismo, se debe a una serie de características, eventos y variables, y no tiene una sola explicación. ¿Qué puede explicar el creciente desencanto con la política estadounidense en relación a las intervenciones militares, y por tanto explicar los cambios similares en la opinión pública sobre las guerras de Irak y Afganistán? Son varios los factores que influencian los cambios en la opinión pública en guerras de esta naturaleza.

En los dos casos expuestos anteriormente, por ejemplo, la tendencia a la baja del apoyo público se centró principalmente en el aumento constante de muertes de militares estadounidenses (Merolla \& Zechmeister, 2009). Los costos, tanto en sangre como en dinero, a los ojos de los estadounidenses, superaron los beneficios la guerra. En este sentido, existe la opinión generalizada de que los costos de estas guerras, que sin duda alguna son sumamente elevados, sobrepasan los beneficios. Eichenberg explica que los resultados de análisis estadísticos confirman que el principal objetivo de la intervención militar está fuertemente correlacionado con el apoyo popular. Sin embargo, los riesgos elevados y la cantidad de víctimas son variables que también son estadísticamente significantes (2005, p. 142).
Con relación a los resultados de estas guerras, la población estadounidense no evidencia un beneficio material o concreto en las mencionadas guerras, lo cual tiene un impacto determinante en la opinión pública. Las dificultades y complicaciones que se presentan al momento de emprender una guerra contra el terrorismo, sin duda alguna sobrepasan los beneficios inmediatos. De acuerdo con esta explicación, los eventos son, en última instancia, la fuerza impulsora detrás de la opinión pública, superando vigorosos esfuerzos de publicitar a la guerra como un esfuerzo indispensable para proteger los intereses nacionales más vitales (Holsti, 2012, p. 148).

\section{La guerra contra el Estado Islámico: perspecti- va a futuro}

Observando la tendencia a la variación que existe en la opinión pública estadounidense con relación al tema de la guerra contra el terrorismo, cabe preguntarse si el apoyo que existe actualmente hacia la alternativa de combatir al Estado Islámico va a perdurar conforme el tiempo pase. La guerra contra el Estado Islámico inicia con niveles similares de aceptación a aquellos presentados a inicios de las guerras en Irak y Afganistán, pues inicia también como respuesta a organizaciones terroristas que se presentan como amenazas. De esta manera, tanto la experiencia de guerras pasadas como las circunstancias existentes al momento pueden llevarnos a la conclusión de que la opinión pública con relación a esta guerra tendrá las mismas tendencias que las mencionadas guerras pasadas.

Un elemento importante a considerar al analizar la guerra contra el Estado Islámico es el hecho de que esta guerra cuenta con precedentes, es decir, guerras pasadas con objetivos similares, que sirven como punto de referencia al momento de realizar un análisis sobre sus beneficios y costos. Esta guerra inicia en una época en el cual la gente cuenta con el precedente de que las guerras pasadas no trajeron beneficios directos, pues actualmente no consideran vivir en un mundo más seguro, aún después de las intervenciones militares pasadas que buscaron combatir el terrorismo. Adicionalmente, en base a la experiencia previa con grupos similares como Al Qaeda, la población es hoy capaz de reconocer que es utópico e irrealista pensar que es posible destruir o 'erradicar' al Estado Islámico. A futuro, por tanto, esta guerra contará con 
cifras elevadas de apoyo popular en los momentos en los que se evidencien resultados exitosos de la misma, o en aquellos en los que eventos como ataques resalten su justificación y necesidad.

Por otro lado, y como complemento a los cuestionamientos que nacen de los precedentes sobre beneficios y costos de las guerras, las dudas sobre si existe o no una verdadera amenaza por parte del grupo también juega un papel importante sobre la opinión pública. Ha sido ya mencionado que a finales de agosto de 2014, a pocos días de la decapitación e los periodistas estadounidenses, un $67 \%$ de estadounidenses consideró que el Estado Islámico es una amenaza seria para la seguridad nacional de los Estados Unidos. Este fue un fenómeno similar al ocurrido tras los atentados en Londres: el apoyo a la guerra en Irak se disparó, positivamente, pues se evidenció una amenaza. Sin embargo, las guerras pasadas evidencian que el porcentaje de la población que considera a estas organizaciones como amenazas para la seguridad disminuye significativamente cuando estas no cometen actos de terror específicos contra Estados Unidos o sus aliados.

A pesar de los altos niveles de apoyo que la guerra contra el Estado Islámico tiene entre la población estadounidense, el porcentaje de individuos que considera que Estados Unidos está, en general, 'ganando' la guerra contra el terrorismo se encuentra en los niveles más bajos de los últimos 10 años. De acuerdo a la encuesta realizada por Rassmussen Reports en julio de 2014, solamente un $27 \%$ de estadounidenses considera que Estados Unidos está teniendo éxito en la guerra contra el terrorismo. Esto indica, desde ya, el impacto que la experiencia de guerras pasadas, en cuanto a los resultados que estas guerras presentaron, se encuentran ya determinando el apoyo de la ciudadanía hacia la actual intervención militar. Como explican Gelpi, Reifler y Feaver, la ciudadanía estadounidense generalmente tolera los costos de las guerras, y las muertes de militares estadounidenses, si consideran que el país tiene posibilidades de ganar en el conflicto (2009, p. 246), lo cual actualmente se encuentra en duda como consecuencia de los resultados de guerras pasadas.

\section{Conclusión}

Tanto la experiencia de guerras pasadas como las circunstancias existentes al momento indican que la opinión pública con relación a la guerra contra el Estado Islámico tendrá las mismas tendencias que las mencionadas guerras pasadas. La guerra contra el Estado Islámico tiene hoy un apoyo mayoritario entre la población estadounidense, como lo hacían las guerras de Irak y Afganistán. Sin embargo, al tomar en cuenta los factores previamente expuestos, es posible que el vasto apoyo con el que cuenta en la actualidad no sea sostenible. Las guerras pasadas han planteado dudas sobre la sostenibilidad del apoyo ciudadano a las intervenciones militares en general, y con relación a la guerra contra el Estado Islámico, estas guerras se presentan hoy como precedentes importantes y determinantes al momento de formular opiniones sobre los beneficios de la misma.

Esto se debe a la existencia de guerras pasadas que terminaron con poco éxito y conllevaron al reconocimiento público de que los costos de estas guerras son sumamente elevados. De igual manera, las percepciones existentes sobre el terrorismo en general son sumamente cambiantes. Los grupos terroristas que Estados Unidos pretende combatir operan, geográficamente, en regiones apartadas al mencionado país, por lo que no son una amenaza inmediata e inminente en la vida diaria de los ciudadanos estadounidenses. Esto, sin duda alguna, afecta a la opinión pública sobre el terrorismo y la guerra contra el mismo, pues no existe, de manera constante, una percepción generalizada de terror, a pesar de que la gente reconoce que sí existe una amenaza.

A lo largo de este análisis se ha demostrado también que son evidentes los aumentos en el apoyo a la intervención militar tras eventos catastróficos como atentados terroristas, amenazas específicas, etc., así como el decrecimiento del mencionado apoyo tras fracasos de las operaciones militares, o en momentos en los que no existen amenazas explicitas. No obstante, ahora existe una noción generalizada de que no existe una estrategia concreta y específica para combatir al grupo, y sobre todo, una creencia de que existe una inminente imposibilidad de alcanzar los objetivos esperados. El público hoy está consciente de que en el mejor de los casos, el resultado de la guerra contra el Estado Islámico será deslegitimarlo, y 
como sucedió con Al Qaeda, ponerlo en una situación en la cual emprender ataques le resulta difícil, pero no eliminarlo como se propone.

\section{Referencias}

Bennett, W., \& Barber, J. (1980). Public opinion in American politics. New York: Harcourt Brace Jovanovich.

Burstein, P. (2014). American public opinion, advocacy, and policy in Congress, en What the public wants and what it gets. Oxford: Oxford University Press.

Davis, P. (2012). Understanding and influencing public support for insurgency and terrorism. California: RAND.

Dimaggio, A. (2010). When media goes to war: Hegemonic discourse, public opinion, and the limits of dissent. New York: Monthly Review Press.

Eichenberg, R. (2005). Victory Has Many Friends: U.S. Public Opinion and the Use of Military Force. International Security, 30(1).

Erikson, R., \& Tedin, K. (2011). American Public Opinion. Boston: Longman.

Gamarra, Y. (2007). La defensa preventiva contra el terrorismo internacional y las armas de destrucción masiva: una crítica razonada. Revista CIDOB d'Afers Internacionals, (77).

Gelpi, C., Reifler, J., \& Feaver, P. (2009). Paying the Human Costs of War : American Public Opinion and Casualties in Military Conflicts. Princeton: Princeton University Press.

Hart Research Associates/Public Opinion Strategies (2014). Study \#14901, NBC News/Wall Street Journal Survey, Recuperado desdes http:// newscms.nbcnews.com/sites/newscms/files/14901_september_nbc-wsj_poll.pdf,_September 2014

Holsti, O. R. (2011). American public opinion on the Iraq War. Ann Arbor: University of Michigan
Press.

Kumar, D. (2012). Islamophobia and the politics of empire. Chicago: Haymarket Books.

Merolla, J., \& Zechmeister, E. (2009). Democracy at risk: How terrorist threats affect the public. Chicago: University of Chicago Press.

Schwarz, B. C.(1994). Casualties, public opinion \& U.S. military intervention: Implications for U.S. regional deterrence strategies. Santa Monica: Rand.

Shapiro, R., \& Jacobs, L. (2011). The Oxford handbook of American public opinion and the media. Oxford: Oxford University Press.

Sobel, R., Furia, P., \& Barratt, B. (2012). Public opinion \& international intervention: Lessons from the Iraq War. Washington, D.C: Potomac Books.

Tirman, J. (2011). The deaths of others: The fate of $\mathrm{ci}$ vilians in America's wars. New York: Oxford University Press.

Rasmussen Reports (2014). War on Terror Update, Survey of 1,000 Likely Voters conducted on October 28-29, 2014. Recuperado desde: http://www.rasmussenreports.com/public content/politics/mood_of_america/war_on terror_update

Rasmussen Reports (2014). 73\% Worry About Obama's Lack of Strategy for ISIS, Survey of 1,000 Likely Voters. Recuperado desde http://www. rasmussenreports.com/public_content/politics/general_politics/september_2014/73_worry_about_obama_s_lack_of_strategy_for_ isis.

Washington Post-ABC News poll (2013). Random national sample of 1,001 adults, including landline and cell phone-only respondents, Recuperado desde http://apps.washingtonpost. com/g/page/politics/post-abc-poll-march-7-10-2013/70/ 